\title{
DESEMPENHO DE CULTIVARES DE AMENDOIM NAS CONDIÇÕES DE CAMPO VERDE-MT
}

\author{
Valéria Santin ${ }^{1}$, Alexandre Caetano Perozini ${ }^{2}$, Charles de Araújo ${ }^{2}$, Felipe Gabriel Giron ${ }^{1}$, Jair Heuert ${ }^{3}$, \\ Maxuel Fellipe Nunes Xavier ${ }^{1}$ e Taís de Moraes Falleiro Suassuna ${ }^{3}$
}

\begin{abstract}
${ }^{1}$ Discentes de Agronomia do IFMT Campus São Vicente - Centro de Referência de Campo VerdeMT, valeriasantin545@gmail.com (Apresentadora do trabalho); ${ }^{2}$ Docentes do IFMT Campus São Vicente - Centro de Referência de Campo Verde-MT; ${ }^{3}$ Núcleo Cerrado - Embrapa, Santo Antônio de Goiás-GO
\end{abstract}

RESUMO: As regiões produtoras de amendoim dispõem de características distintas em relação ao clima e tipo de solo. Por essa razão é necessário a utilização de cultivares que melhor se adaptam a cada condição. O presente trabalho teve por objetivo analisar as características agronômicas e produtividade dos diferentes cultivares, nas condições de Cerrado do Mato Grosso. O experimento foi realizado na área experimental do Instituto Federal de Educação, Ciências e Tecnologia de Mato Grosso - Campus São Vicente, Centro de Referência de Campo Verde localizada no município de Campo Verde - MT. Os tratamentos constam de diferentes cultivares de amendoim rasteiro: BRS 425, BRS 423, BRS 421, IAC 503 e IAC OL 3. O delineamento experimental foi o de blocos casualizados, com 4 repetições. As parcelas corresponderam a 2 linhas de $3 \mathrm{~m}$ de comprimento, com espaçamento entre linhas de $90 \mathrm{~cm}$. Foi avaliado a massa de 100 grãos, severidade de mancha preta e produtividade de vagens. As cultivares BRS 421, IAC 503 e BRS 423 apresentam menor susceptibilidade ao ataque de mancha preta. A maior massa de 100 grãos foi encontrada na cultivar BRS 421. Todas as cultivares apresentaram um desempenho semelhante nas condições experimentais.

Palavras-Chave: Arachis hypogaea L., cultivares de amendoim, adaptação.

\section{INTRODUÇÃO}

O amendoim é uma planta da família Fabaceae, gênero Arachis, que conta com um grande número de espécies conhecidas, dentre as quais, Arachis hypogaea L. que é a única cultivada para consumo humano (CÂMARA, 2016). A espécie é produzida em diversos países ao redor do mundo, em pequenas áreas pela agricultura familiar, como em grandes extensões com utilização de alto nível tecnológico.

No Brasil, estima-se que a produção de amendoim safra 2018/19 será de 430,8 mil toneladas, com uma redução de $19 \%$ em relação à safra passada, onde foi produzido 511,4 mil toneladas. A 


\section{Encontro Sobre a Cultura do Amendoim \\ 15 a 17 de agosto de 2019 na Estação de Eventos Cora Coralina e FCAV/UNESP, Jaboticabal-SP}

produção nacional se concentra na região sudeste, em especial no Estado de São Paulo que corresponde com cerca de $90 \%$ da produção (CONAB, 2019).

Para atender ao mercado agroindustrial do amendoim foi desenvolvido cultivares com presença de um maior teor de ácido oleico nos óleos que compõem o grão. Enquanto os amendoins tradicionais têm de $40 \%$ a 50\% de ácido oleico na composição, as cultivares novas possuem de 70\% a 80\% do teor de acido oleico na composição (CÂMARA, 2016). A característica de alto teor de ácido oleico nos grãos tem sido uma exigência mercadológica, conferindo uma maior vida útil de prateleira evitando a oxidação do produto (WANG et al., 2015). Nas últimas safras, vem sendo utilizado cultivares de porte rasteiro, de ciclo ao redor de 130 a 140 dias, com características favoráveis para mecanização e um maior potencial produtivo (GODOY, 2015).

O programa de melhoramento de amendoim para o cerrado brasileiro teve início em 2010 , estudando as fontes de variabilidade comerciais de genótipos com alto oleico, germoplasma precoce e linhagens interespecíficas (SUASSUNA et al., 2015). O desenvolvimento de cultivares tipo "Runner" a ser adaptado à região Centro-Oeste é um dos objetivos do programa de melhoramento da Embrapa. Segundo Uitdewilligen et al. (2018) é preciso conhecer o desempenho dos cultivares selecionados em outros locais do Brasil para poder atender a demanda do mercado de sementes comerciais de amendoim.

As informações ainda são incipientes do desempenho agronômico de cultivares de amendoim no estado do Mato Grosso. Objetivo desse trabalho foi avaliar a produtividade, massa de 100 grãos e severidade de mancha preta das cultivares BRS 425, BRS 423, BRS 421, IAC 503 e IAC OL 3.

\section{MATERIAL E MÉTODOS}

O experimento foi desenvolvido no ano agrícola de 2018/19 com semeadura realizada manualmente no dia 05-11-18, na área experimental do Instituto Federal de Educação, Ciências e Tecnologia de Mato Grosso - Campus São Vicente, Centro de Referência de Campo Verde localizada no município de Campo Verde - MT.

O delineamento experimental utilizado foi em blocos casualizados, com quatro repetições. Os tratamentos constataram de cinco cultivares de amendoim rasteiro: BRS 425, BRS 423, BRS 421, IAC 503 e IAC OL 3. As parcelas eram compostas de duas linhas de três metros de comprimento, com espaçamento entre linhas de noventa centímetros, intervalo entre parcelas de dois metros e parcela útil de 5,4 metros $^{2}$.

Os manejos cultural e fitossanitário foram realizados de acordo com as recomendações. $\mathrm{O}$ estande médio estabelecido de plantas foi de 18 plantas $\mathrm{m}^{-1}$, ao final do ciclo da cultura assim que as vagens atingiram o ponto de maturação foi realizado a colheita. Os componentes de produtividade foram avaliados por meio da pesagem das vagens, obtidas dos 3,6 metros ${ }^{2}$ centrais da parcela. Das 


\section{Encontro Sobre a Cultura do Amendoim \\ 15 a 17 de agosto de 2019 na Estação de Eventos Cora Coralina e FCAV/UNESP, Jaboticabal-SP}

plantas colhidas foram feitas as avaliações de massa de 100 grãos e produtividade de vagens. A severidade de mancha preta (Cercosporidium personatum) foi avaliada usando a escala diagramática da incidência com notas de 1 a 9 ao final do ciclo das cultivares (SUBRAHMANYAM et. al., 1982).

Os dados obtidos foram submetidos à análise de variância (Teste F) e as médias dos tratamentos foram comparados pelo teste de Scott-Knott a 5\% de probabilidade, por meio do programa computacional SISVAR 5.6 (FERREIRA, 2014).

\section{RESULTADOS E DISCUSSÃO}

Pelos dados apresentados na Tabela 1, pode ser observado que as diferentes variedades de amendoim apresentaram diferença significativa para massa de 100 grãos (g) e severidade de mancha preta (escala de nota). Para a produtividade de vagens $\left(\mathrm{kg} \mathrm{ha}^{-1}\right.$ e sacas.alqueire $\left.{ }^{-1}\right)$ as diferentes cultivares de amendoim não diferiram significativamente entre si.

Tabela 1. Massa de 100 grãos (g), severidade de mancha preta (escala de nota), produtividade de vagens ( $\mathrm{kg} \mathrm{ha}^{-1}$ e sacas/alqueire) em função das diferentes cultivares de amendoim. Campo Verde-MT, 2018/19.

\begin{tabular}{ccccc}
\hline \multirow{2}{*}{ Cultivares } & $\begin{array}{c}\text { Massa de 100 } \\
\text { grãos }\end{array}$ & $\begin{array}{c}\text { Severidade de } \\
\text { mancha preta }\end{array}$ & \multicolumn{2}{c}{ Produtividade de vagens } \\
\cline { 2 - 5 } & $(\mathrm{g})$ & (Escala de nota) & $\left(\mathrm{kg} \mathrm{ha}^{-1}\right)$ & (sacas.alqueire $\left.^{-1}\right)$ \\
\hline IAC 503 & $72,0 \mathrm{~b}$ & $6,08 \mathrm{a}$ & $6.837,0 \mathrm{a}$ & $661,8 \mathrm{a}$ \\
BRS 421 & $79,3 \mathrm{a}$ & $6,31 \mathrm{a}$ & $6.711,1 \mathrm{a}$ & $649,6 \mathrm{a}$ \\
BRS 425 & $68,0 \mathrm{~b}$ & $6,95 \mathrm{~b}$ & $6.407,4 \mathrm{a}$ & $620,2 \mathrm{a}$ \\
IAC OL 3 & $67,0 \mathrm{~b}$ & $7,77 \mathrm{~b}$ & $6.251,4 \mathrm{a}$ & $605,1 \mathrm{a}$ \\
BRS 423 & $67,5 \mathrm{~b}$ & $6,36 \mathrm{a}$ & $5.947,9 \mathrm{a}$ & $575,7 \mathrm{a}$ \\
\hline F calculado & $0,0006^{*}$ & $0,0175^{*}$ & $0,0381^{\mathrm{ns}}$ & $0.0381^{\text {ns }}$ \\
\hline C.V.\% & 5,47 & 9,92 & 6,07 & 6,07 \\
\hline
\end{tabular}

Fonte: Elaboração pelo próprio autor, 2019; * - Significativo a 5\% de probabilidade pelo teste de Scott-Knott; ns - não significativo; C.V. - Coeficiente de Variação.

As cultivares avaliados apresentaram diferenças quanto a escala de notas relacionadas a severidade de mancha preta. O IAC OL 3 foi o mais suscetível e por isso obteve nota de severidade de 7,7 , seguido pelo BRS 425 com nota 6,95 . A menor severidade foi observada nas cultivares BRS 423 $(6,36)$, BRS $421(6,31)$ e IAC $503(6,08)$.

Observa-se que a maior massa média de 100 grãos foi na cultivar BRS 421 (79,3 g) seguido do IAC 503 (72,0 g). As cultivares BRS 425, BRS 423 e IAC OL 3 não diferiram significativamente entre si e apresentaram redução de 14,2; 14,9 e 15,5\% na massa média em relação ao BRS 421. Estes resultados concordam com Ribeiro et al. (2018) que observou maiores massas de 100 grãos com as 


\section{Encontro Sobre a Cultura do Amendoim \\ 15 a 17 de agosto de 2019 na Estação de Eventos Cora Coralina e FCAV/UNESP, Jaboticabal-SP}

variedades BRS 421 (13-374) com valor de $88 \mathrm{~g}$, e o IAC 503 com massa de 89,1 g nas mesmas configurações de semeadura, em Tupã-SP.

Apesar de não ter ocorrido diferenças significativas entre as cultivares para a produtividade de vagens, todas superaram nas condições experimentais a produtividade de $5.500 \mathrm{de} \mathrm{kg}$ de amendoim em vagens por ha ${ }^{-1}$. Informações complementares devem ser consideradas para cultivo em uma escala maior, visando explorar a melhor adaptação ao ambiente estudado.

\section{CONCLUSÕES}

Nas condições experimentais em que foi desenvolvida esta pesquisa, pode-se concluir que:

- As menores notas de severidade de mancha preta foram nas cultivares IAC 503, BRS 421 e BRS 423.

- A maior massa de 100 grãos foi encontrada na cultivar BRS 421. As cultivares IAC 503, BRS 425, BRS 423 e IAC OL 3 tiveram uma massa de 100 grãos semelhantes.

- Todas cultivares tiveram uma produtividade acima de $5.500 \mathrm{~kg}$ de amendoim em vagens por ha $^{1}$. Sugere-se para um cultivo comercial sejam realizados alguns testes complementares em escala maior para observar a sua adaptabilidade as condições edafoclimáticas do Cerrado Matogrossense.

\section{AGRADECIMENTOS}

Os autores agradecem o Instituto Federal de Educação, Ciências e Tecnologia de Mato Grosso - Campus São Vicente, Centro de Referência de Campo Verde e ao Núcleo Cerrado da Embrapa Algodão, localizado em Santo Antônio do Goiás-GO pelo apoio.

\section{REFERÊNCIAS BIBLIOGRÁFICAS}

CÂMARA, G.M.S. Estudo da planta do amendoim. USP-LPV-506: Plantas oleaginosas- A planta do amendoim, 2016. 20 p.

COMPANHIA NACIONAL DE ABASTECIMENTO - CONAB: Acompanhamento da Safra Brasileira de grãos, v. 6 Safra 2018/19 - Sétimo levantamento, Brasília, p. 1-119, abril 2019.

GODOY, I.J. Como São denominados os tipos de amendoim. Disponível em: <http://infoamendoim.com.br/site/amendoim-habito-de-crescimento-padrão-de-ramificacao-e-ciclo/ > Acesso em: 6 maio 2019.

FERREIRA, D. F. Sisvar: A Guide for its Bootstrap procedures in multiple comparisons. Ciênc. agrotec. [online]. 2014, v.38, n.2, pp. 109-112. Disponível em: <http://dx.doi.org/10.1590/S141370542014000200001>. Acesso em: 6 maio 2019. 


\section{Encontro Sobre a Cultura do Amendoim}

\section{5 a 17 de agosto de 2019 na Estação de Eventos Cora Coralina e FCAV/UNESP,}

Jaboticabal-SP

RIBEIRO, R.P.; SUASSUNA, T.M.F.; HEUERT, J.; SOAVE, J.H.; SANTOS, L.C.C. Desempenho de genótipos de amendoim na Alta Paulista. In: Anais do Encontro Sobre a Cultura do Amendoim, 2018. Anais eletrônicos... Campinas, GALOÁ, 2018.

SUASSUNA, T. M. F.; SUASSUNA, N. D.; MORETZSOHN, M. C.; BERTIOLI, S. C. M. L.; BERTIOLI, D. J.; MEDEIRO, E. P. Yield, market quality, and leaf spots partial resistance of interspecific peanut progenies. Crop Breed. Appl. Biotechnol., Viçosa, v.15, n.3, p.175-180, 2015. SUBRAHMANYAM, P.; MCDONALD, D.; GIBBONS, R. W.; NIGAM, S. N.; NEVILL, D.J. Resistance to rust and late leaf spot diseases in some genotypes of Arachis hypogaea. Peanut Science, v.9, p.9-14, 1982.

UITDEWILligen, G. S.; REICH, T. C.; CAPORUSSO, N. B.; SUASSUNA, N. D.; HEUERT, J.; SUASSUNA, T. M. F. Avaliação do desempenho de linhagens de amendoim em Jaboticabal, São Paulo, via modelos mistos. In: Anais do Encontro Sobre a Cultura do Amendoim, 2017. Anais eletrônicos... Campinas, GALOÁ, 2018.

WANG, X.Z.; TANG, Y.Y.; WU Q.; SUN Q.X.; WANG Y.Y.; HU D.Q.; WANG C.T.; 2015 Characterization of high-oleic peanut natural mutants derived from an intersectional cross. Grasas $\mathbf{y}$ Aceites. 66. 10.3989/gya.1070142. Disponível em: <http://dx.doi.org/10.3989/gya.1070142〉. Acesso em: 31 maio 2019. 